\title{
Gedanken über Li Bais Jing ye si (Gedanken in einer stillen Nacht) und dessen Vertonungen im Westen
}

\section{Thoughts on Li Bai's Jing Ye Si (Quiet Night Thought) and Its Musical Settings in the West}

\begin{abstract}
Neither the object, the subject, the action, the scene, the place nor time is clearly defined in Li Bai's poem Jing ye si. The poem remains open, to a certain extent even empty, and cannot be clearly interpreted. Statements about the poem are thus comparable to self-generated illusions. Jing ye si is the second most frequently set poem of Li Bai in the West. But just as some translators have arbitrarily introduced new images in their translations, composers have also often imparted affects and moods that are not actually found in Jing ye si.
\end{abstract}

\section{Ein leeres Gedicht}

Stellen wir uns ein Bett und einen Boden vor. Auf dem Boden vor dem Bett leuchtet etwas. Ist es das Licht des Mondes? Oder etwa Reif? Mit dieser Szenerie und dem Zweifel an der eigenen Perzeption beginnt Li Bais Gedicht 静夜思 Jing ye si (still Nacht - Gedanken; Gedanken in einer stillen Nacht).

$\begin{array}{ll}\text { 床前明月光， } & \text { Chuang qian ming yue guang, } \\ \text { 疑是地上霜。 } & \text { Yi shi di shang shuang. } \\ \text { 舉頭望明月， } & \text { Ju tou wang ming yue, } \\ \text { 低頭思故鄉。 } & \text { Di tou si gu xiang. }{ }^{1}\end{array}$

In wörtlicher Übertragung: ${ }^{2}$

Bett - davor - hell - Mond - Lichtschein
zweifeln - sein - Boden - obendrauf - Frost (oder Reif)

DOI: $10.26045 /$ po-017

1 Zit. nach www.shicimingju.com/chaxun/list/3501.html (Zugriff 20.07.2020).

2 Für Übertragungen des Gedichts und hilfreiche Erklärungen bedanke ich mich herzlich bei Marc Winter. 
Heben - Kopf - in die Ferne sehen - hell - Mond

Senken - Kopf - denken an - alt - Heimat.

Die chinesische Fassung des Gedichts kann in ihrer Kürze (pro Silbe ein Wort), in ihrer Metrik (fünf Silben und Zäsur nach der zweiten), Reimstruktur (aaba) und ihren Parallelen - die Verse drei und vier sind grammatikalisch parallel aufgebaut (Verb-NomenVerb-Adjektiv-Nomen) und zudem antithetisch in ihrem Inhalt (Kopf heben, Kopf senken) - kaum in andere Sprachen übertragen werden. Alfred Forke musste für seine Übertragung von 1899 die Verslänge verdoppeln, hielt aber am Metrum fest:

\author{
Vor meinem Bette \\ Ich Mondschein seh', \\ Als wär' der Boden \\ Bedeckt mit Schnee. \\ Ich schau' zum Mond auf, \\ Der droben blinkt, \\ Der Heimath denkend \\ Das Haupt mir sinkt. ${ }^{3}$
}

Das Jing ye si mag ein gutes Beispiel sein, um eine Hauptannahme der skeptischen Philosophie, einerlei ob in Gestalt der pyrrhonischen Skepsis oder des skeptischen Buddhismus, zu veranschaulichen: dass die Dinge nur in Wandlung, im Zusammenhang mit anderen Dingen und relativ zu inneren und äußeren Umständen wahrgenommen werden, ${ }^{4}$ sie in diesem Sinne leer zu sein scheinen, das heißt nicht von sich aus auf irgendeine Substanz, ihre Definition oder ihren kausalen Grund verweisen. Mit dem Wort >leer ist nicht ein ontologisches Nichts als Nicht-Sein gemeint, sondern ein epistemologisches Nichts. ${ }^{5}$ Leer sind Erscheinungen, die bei Enthaltung eines Urteils darüber, was die Erscheinungen sein sollten, wahrgenommen werden. Hört das bestimmende und unterscheidende Denken auf, so sind die Erscheinungen der Umwelt leer, formulierten es Huangbo Xiyun 黃檗希運 $(† 850)$ oder Linji Yixuan 臨濟義玄 $\left(†\right.$ 866/867). ${ }^{6}$ Umgekehrt sind Erscheinungen, die dogmatisch als so und so gedeutet werden, letztlich selbsterzeugte Illusionen oder Halluzinatio-

Alfred Forke: Blüthen chinesischer Dichtung. Aus der Zeit der Han- und Sechs-Dynastie, Magdeburg: Faber, 1899, S. 145.

4 Was die pyrrhonische Skepsis z. B. anhand der zehn Tropen zu zeigen versucht, vgl. Sextus Empiricus: Grundriß der pyrrhonischen Skepsis, übers. von Malte Hossenfelder, Frankfurt am Main: Suhrkamp, 1985, S. 102-130 (I, 36-163).

5 Vgl. z. B. Nagarjuna: Die Lehre von der Mitte (Mula-madhyamaka-karika / Zhong Lun), übers. von Lutz Geldsetzer, Hamburg: Meiner, 2010, S. 40 f. (XIII, 3 und 8); vgl. auch »The Heart Sutra", in: Richard H. Jones: The Heart of Buddhist Wisdom. Plain English Translations of the Heart Sutra, the Diamond-Cutter Sutra, and other Perfection of Wisdom Texts, New York: Jackson Square Books, 2012, S. 198.

6 Vgl. Huang Po: Der Geist des Zen. Die legendären Aussprüche und Ansprachen des Huang-po, übers. von Ursula von Mangoldt, München: O. W. Barth, 2011, S. 56; vgl. Linji: Das Denken 
nen. ${ }^{7}$ Gemäß selbstauflösender Logik der radikalen Skepsis - diese sei, so Diogenes Laertius, gleich wie Linji, nur ein Abführmittel für (an Metaphysik) Erkrankte ${ }^{8}-$ wären nun Erscheinungen, die bei vollkommener Urteilsenthaltung wahrgenommen werden, auch nicht mehr leer, zumal auch dies nur ein Begriff oder eine dogmatische Behauptung wäre, sondern weder leer noch nicht-leer. Damit zugunsten des Textes noch etwas Beschreibbares übrigbleibt, sei für die Lektüre des Jing ye si allerdings auf diese Ebene der Skepsis ${ }^{9}$ verzichtet. Ferner sei eine Identität zwischen den Erscheinungen des Jing ye si und den Vorstellungen, die beim Lesen der Wörter des Gedichts geweckt werden, angenommen. Wenn die Wörter leer erscheinen, hat das Gedicht viele relative, aber keine klare Aussage mehr. Um dies zu zeigen, sollen einzelne Elemente genauer untersucht werden: die Objekte, das Subjekt und dessen Handlung, die Zeit und der Ort. Die folgenden Ausführungen beziehen sich auf die deutsche Interlinearübersetzung und nicht auf die chinesische Originalfassung. Was Li Bai mit dem Gedicht beabsichtigt haben mag oder wie es in der Tang-Zeit rezipiert wurde, soll vorerst keine Rolle spielen.

Sieben Objekte kommen im Gedicht vor - Bett, Boden, Mond, Reif, Leuchten, Kopf und Heimat; zwei im Titel, Nacht und Gedanken. Was ist die Heimat? Niemand weiß es, vielleicht ein schönes an frühere Erinnerungen geknüpftes Gefühl, vielleicht ein übles, vielleicht aber auch schlicht ein Begriff ohne Aussage. Nach dieser Deutung würde das Subjekt den Kopf senken, weil es den Begriff nicht fassen kann. Kommen wir zum Kopf, einem schwer fassbaren Wort, dessen Gegenstand und Sinn - anders als etwa jener des Wortes Besen, in dem Besenstiel und Bürste verborgen sein mögen ${ }^{10}$ - nicht einmal, falls wir an den Kopf eines Wurmes denken, Augen oder Nase enthalten muss. Vermutlich ist es Etwas mit einem Mund oder einer Öffnung. Vielleicht auch ein Nichts wie der Kopf des Chemikers Griffin. »Bis zum Rockkragen hinauf« war Griffin eine »greifbare, gestikulierende Gestalt. [...] Darüber aber war nichts, jedenfalls nichts Sichtbares «. ${ }^{11}$ Das unpräzisierte Leuchten und der Reif scheinen als Objekte selbst undefinierbar zu sein. Leuchten kann das Mondlicht, eine Glühbirne oder eben der Reif. Mit dem Mond ist wahrscheinlich die sichtbare Hälfte des Erdmondes gemeint, obschon es sich auch um den Mond

ist ein wilder Affe. Die Lehren des großen Zen-Meisters, übers. von Ursula Jarand, München: O. W Barth, 2015, S. 76.

7 Vgl. z. B. Huang Po: Der Geist des Zen, S. 115 f. und 139; Linji: Das Denken ist ein wilder Affe, S. 105.

8 Vgl. Diogenes Laertius: Leben und Meinungen berühmter Philosophen, übers. von Otto Apelt, hg. von Klaus Reich, Hamburg: Meiner, 2008, Bd. 2, S. 187 (IX, 76); Linji: Das Denken ist ein wilder Affe, S. 75 und 122.

9 Vgl. z. B.»The Heart Sutra", in: Jones: The Heart of Buddhist Wisdom, S. 199 (The Fourth Meditative Level).

10 Vgl. Ludwig Wittgenstein: Philosophische Untersuchungen, in: ders.: Tractatus logico-philosophicus, Tagebücher 1914-1916, Philosophische Untersuchungen, Frankfurt am Main: Suhrkamp, 1984 (Ludwig Wittgenstein Werkausgabe, Bd. 1), S. 225-580, hier S. 274 (Nr. 60).

11 Vgl. Herbert George Wells: Der Unsichtbare, übers. von Brigitte Reiffenstein und Alfred Winternitz, München: dtv, 1996, S. 54. 
eines anderen Planeten handeln könnte. Wie mag der Boden im Gedicht definiert werden? Gar nicht. Er könnte nur aus Erde bestehen oder aus Wurzeln und Moos, aus Steinplatten, Holzdielen oder sonst was - ein unebener Boden zumindest könnte die Halluzination von unebenem Reif im zweiten Vers besser erklären - ferner entweder von endlicher oder unendlicher Ausbreitung sein, womöglich auch von endlicher und unendlicher Ausbreitung zugleich oder weder von endlicher noch unendlicher. Ebenso unklar ist der Begriff Bett. Ein Bett könnte Füße haben oder keine, aus einer einzelnen Matte bestehen oder nur aus Pflanzenbündeln oder Fellen. Über den Begriff Gedanken sei gar nicht erst irgendetwas behauptet. Wir sehen somit - keines der bei Li Bai erwähnten Objekte kann klar gedeutet werden. Wenn beim Lesen der leeren Wörter eine bestimmte Vorstellung erzeugt wird, etwa eines Bodens, dann handelt es sich um eine Spiegelung der eigenen Phantasie.

Wo ereignen sich die Szenen? Da ein Bett und ein Boden vorkommen, in einem Haus, vielleicht. Doch könnte das Bett aus Heu bestehen und der Boden aus Erde, womit die Szenerie eher außerhalb eines Hauses stattfände. Außerdem werden nirgends im Gedicht Fenster, Türen, Wände und andere Elemente erwähnt. Es müsste sich demnach um eines jener Häuser ohne Wände handeln, die der Gelehrte und Philosoph De Selby entwickelt hatte. ${ }^{12}$ Wenn der Ort nicht klar ist, dann vielleicht der Ort des Ortes? Auch dies nicht. Das Gedicht könnte in China spielen, genauso gut wie im Engadin, draußen im Universum oder außerhalb von diesem. Ist die Jahreszeit oder das Jahr der Handlung bekannt? Mitnichten. Reif ist zu vernehmen, somit mag die Szenerie im späten Herbst oder frühen Winter stattfinden, meinte J. P. Seaton. ${ }^{13}$ Entgegnet wäre, dass Reif auch im Frühling oder Sommer vorkommen kann und derjenige des Gedichtes sich zudem als Illusion der Perzeption auflöst. So wie die Jahreszeit der Szenerie unbekannt ist, so auch das Jahr; allenfalls eines aus der Tang-Zeit, vielleicht aus der Prähistorie oder Zukunft.

Betrachten wir das Subjekt und dessen Denken und Handeln. Wer sieht das Mondlicht und meint kurzzeitig Reif zu erblicken? Ein Mann? Vielleicht. Vielleicht auch eine Frau oder ein Kind. Eine nähere Bestimmung wäre im Hinblick auf die Leere der Wörter nur ein »Produkt des Denkens « ${ }^{14}$ Womöglich ist das Subjekt auch weder Frau noch Mann noch Kind, hingegen ein Wildschwein, denn auch sie haben ihre Kessel oder Betten, sehen Mond und Reif, haben einen Kopf zum Heben und Senken und dazu ein Revier, eine Heimat. Das Subjekt bleibt also unbestimmt. Gänzlich unklar ist zudem der Grund seiner Handlung. Warum zweifelt es, ob das Leuchten vom Mond oder vom Reif kommt? Mag sein, dass es eben aufgewacht und im Denken noch verwirrt ist. Mag aber auch nicht sein, denn vielleicht befindet sich das Subjekt seit Stunden schon außerhalb des Bettes und weilt irgendwo im Raum. Vielleicht war das Subjekt noch betrunken und verwechselte den leuchtenden Bo-

Vgl. Flann O’Brien: Der dritte Polizist, übers. von Harry Rowohlt, Frankfurt am Main: Suhrkamp, 1991, S. $28 \mathrm{f}$.

13 Vgl. Jerome P. Seaton: Bright Moon, White Clouds. Selected Poems of Li Po, Boulder: Shambhala, 2012, S. 218. 
den mit seiner belegten Zunge. Möglich wäre auch, im Subjekt Betagte zu erkennen, die nicht mehr klar im Kopf sind, oder Skeptiker, die bewusst Sinneswahrnehmungen vermischen, um sich eines metaphysischen Urteils zu enthalten. ${ }^{15}$ Schließlich noch die Frage, warum das Subjekt an die Heimat denkt. Ist es vielleicht von seiner Heimat verbannt oder im Gefängnis eingeschlossen? Schwer vorstellbar in einem Raum ohne Wände, aber warum nicht? Andererseits, warum muss ein Subjekt außerhalb der Heimat sein, um an seine alte Heimat zu denken? Bei Annahme von Betrunkenheit oder hohem Alter denkt es vielleicht an seine Heimat, weil ihm nichts Besseres einfällt. Kurz, wie auch immer man Li Bais Jing ye si deutet und umdeutet, die Wörter selbst sind leer und haben Platz für unendlich viele, teils sich widersprechende, aber immer willkürliche Deutungen.

\section{Kritische Einwände ${ }^{16}$}

Die eben ausgeführte skeptische >Undeutung` des Gedichts kann ihrerseits wieder relativiert werden: Li Bai hätte die Wörter seines Gedichtes keinesfalls als leer oder beliebig deutbar aufgefasst. Dagegen ist nichts einzuwenden. Ich habe das Gedicht skeptisch gelesen, und nicht gemäß Annahmen zu Li Bais Intention oder zum Verständnis seiner Zeitgenoss*innen. Überdies scheint unklar zu sein, welche Fassung des Gedichtes von Li Bai stammt; die hier vorliegende wurde seit der Qing-Dynastie überliefert. Beim Mond hätte der Dichter nur an den Erdmond (yue 月) gedacht, denn zu seiner Zeit hätte niemand von Monden anderer Planeten gewusst. Auch dagegen sei wenig gesagt. Es wäre zwar möglich, sich unabhängig von astronomischen Daten die Existenz weiterer Monde vorzustellen, und der Erdmond, vor allem dessen Rückseite, ist bis heute nicht ganz zu fassen. Das im Gedicht vorkommende Leuchten sei nicht unpräzisiert, hingegen ein ming yue guang 明月光, das Leuchten des hellen Mondes, der Mondschein. Indessen, sei entgegnet, kann das Leuchten des Mondes trotzdem nicht klar definiert sein, ansonsten das Subjekt im Gedicht jenes Leuchten nicht mit Reif oder Frost verwechselt hätte. Manchmal erscheint das Mondleuchten weiß oder silbern, dann wieder, einerlei ob von den Sinneszellen im Auge oder sonst welchen internen oder externen Umständen verursacht, bläulich oder gelblich. Nicht stimmen könne ferner die Gleichsetzung des Subjekts mit einem Wildschwein, denn in der Tang-Zeit hätte man Vorgänge wie zweifeln ( $y i$ 疑) und denken ( $s i$ 思) keinem Tier zugesprochen, ebenso wenig eine alte Heimat ( $g u$ xiang 故鄉). Dazu kann ich wenig sagen, da mir wegen eines Virus die Daten fehlen. ${ }^{17}$ Es wäre jedoch merkwürdig, wenn die Idee eines Bewusstseins und Denkens bei Tieren in der chinesischen Kultur, insbesondere bei skeptischen Denkrichtungen, unbekannt gewesen wäre, wo doch in der westlichen Skepsis seit der Antike

Vgl. Sextus Empiricus: Grundriss der pyrrhonischen Skepsis, S. 122 (I, 124-127).

16 Für diese bedanke ich mich herzlich bei Roman Brotbeck, Hsuan Huang, Eva Schestag und Marc Winter.

17 Die Rede ist vom sogenannten Corona-Virus, die Bibliotheken sind geschlossen (April 2020). 
Chrysippos' Hund, der das fünfte mehrgliedrige unbewiesene Argument anwendet, umherirrt. ${ }^{18}$ Nicht nachvollziehbar sei zudem die Annahme, dass ein menschliches Subjekt im Gedicht an gu xiang 故鄉 innerhalb seiner Heimat denke. Wenn die Schriftzeichen so vorkämen - und das Denken an die Heimat, das heißt einen mit Sehnsucht besetzten Ort der Vergangenheit, sei ein Topos -, dann befände sich das Subjekt außerhalb seiner Heimat. Weil aber der Dichter den Topos in seiner Heimat aufschreiben kann, müsste potenziell auch das lyrische Subjekt in seiner Heimat sich selbst als Subjekt außerhalb seiner Heimat denken können.

Selbst wenn die Unklarheit der Begriffe Mond, Leuchten und Heimat, außerdem die Unklarheit einer Bestimmung des Subjekts im Gedicht, angenommen würde, bliebe noch chuang 床, das Bett des Jing ye si übrig. Fälschlicherweise sei dieses Bett als aus Gräsern oder einer einzelnen Matte bestehend vorgestellt worden. Gräser oder andere Naturalien kämen aber nicht infrage, da der Begriff auf einen menschlich erzeugten Gegenstand verweise und Li Bai für die Darstellung einer Matte, etwa aus Schilf gewebt, das Schriftzeichen 席 $x i$ verwendet hätte. ${ }^{19}$ Chuang hingegen sei ungefähr das, was wir uns heute unter einem Bett vorstellen, und auch ähnlich in seiner Funktion zu deuten, als eine Liegefläche, darauf Menschen ungestört schlafen. ${ }^{20}$ Aus dieser Funktion wäre zusätzlich abzuleiten, dass sich über dem Bett ein Dach befinde. Folglich wären im Gedicht ein Dach impliziert und zugleich Wände oder zumindest Pfosten, die es halten. Nehmen wir diese Kritik an, zumal Li Bai tatsächlich an solche Betten und nicht an Moose gedacht haben mag, und versuchen ein paar Entgegnungen zu formulieren. Das Wort Bett ist zwar verschieden vom Wort Moos, doch nicht weniger vieldeutig und unklar. Genauso unbekannt wie die verschwundene Vielfalt der Betten aus der Tang-Dynastie ist das Aussehen des Gedichtbettes, und zwar selbst wenn wir dessen Typ definitorisch eingrenzen würden. Ob es sich um ein Bett im Gefängnis oder im Kaiserhof handelt, ob seine Umrahmung Verzierungen, Gänge von Termiten oder handschriftliche Notizen eines Verrückten enthält, wären wichtige Informationen für das Verständnis der Gesamtszenerie. Aber solche Informationen fehlen, das Bett mag dies und das sein. Auch die Funktionalität des Begriffs bleibt, trotz Konsens im alltäglichen Sprachgebrauch, vage. Soll auf einem Bett geschlafen werden? Man könnte hie und da auch unter ihm schlafen, wodurch das Bett die Funktion eines Verstecks bekäme. Das Bett als Erscheinung könnte funktional sogar mit dem Begriff Haus bezeichnet werden, beispielsweise aus Sicht eines Gemeinen Nagekäfers. Übernähmen wir diese Deutung für das Jing ye si, könnten wir sogar der wandlosen Häuser des Philosophen De Selby entbehren. Keine Wände mehr würden im Gedicht fehlen; das gesuchte Haus wäre schlicht das Bett. 
Solche konstruierten Relativierungen erzeugen nur Chaos, so die Kritiker. Überhaupt erscheine die Relativierung jedes vereinzelten Gedichtwortes gekünstelt, da weder die Erscheinungen gesondert wahrgenommen werden noch die Wörter gelesen. Wo ein Bett erscheine, da zugleich der Boden, auf dem es stehe und zugleich das Mondleuchten, und nirgends würde ein einzelner Kopf, wäre es sogar jener unsichtbare des Chemikers Griffin, wahrgenommen, vielmehr eine Bewegung, die des Ju tou 舉頭 und Di tou 低頭, des Kopf-Hebens und Kopf-Senkens. Diese Kritik, die sich indirekt auf den skeptischen Tropus Sechs bezieht - Dinge können nie an sich selbst wahrgenommen werden, sondern immer nur in Beimischung mit anderen Dingen $^{21}$ - erweitert die Relativierung der einzelnen Wortbestimmungen. Nicht alleine wäre der Begriff Kopf, dessen Vorstellung im Gedicht untrennbar mit jener der Bewegung, des Mondlichts und der Nacht vermischt zu sein scheint, unklar, nein, er könnte gar nicht an sich definiert werden. Schließlich sei noch kurz die grammatikalische Struktur der antithetischen Verse 3 und 4 erwähnt. Die Beziehung zwischen den Verben der Verse kann im Sinne einer Wenn-Dann-Konstruktion gelesen werden: "Hebe ich den Kopf, sehe ich fern den hellen Mond / Senke ich den Kopf, denke ich an die alte Heimat «. ${ }^{22}$ Wenn also das Subjekt den Kopf nicht senkt, denkt es vielleicht nicht an die Heimat, und wenn es weder den Kopf senkt noch hebt, was immerhin bequemer wäre, würde es womöglich weder den Mond sehen noch an die Heimat denken. Bewegt es aber seinen Kopf regelmäßig auf und ab, folgt eine sinnlose Abfolge von Mond und Heimat, Heimat und Mond, die mit der Zeit selbst noch den letzten Gedanken auslöschen mag.

Falls das Jing ye si trotz Einwänden als leer, als ein Gedicht ohne klare Aussage, aufgefasst wird, worin unterscheidet sich dann seine Leere von der Leere eines anderen Gedichts? Die Leere ist nur Folge einer Urteilsenthaltung, anders formuliert, die deutlose Wahrnehmung der Erscheinungen und ihrer Wandlungen (denn das Gedicht kann bei jeder Lektüre anders erscheinen), weswegen es keinen Unterschied gibt zwischen der Leere eines chinesischen oder rätoromanischen Gedichts. Das Jing ye si ist jedoch ein gutes Beispiel, um zu zeigen, wie willkürlich Deutungen erzeugt werden.

\section{Das Hinzudichten von Deutungen und Vorstellungen}

Alfred Forke übertrug das Jing ye si recht nahe am chinesischen Original, ebenso Hans Heilmann, Otto Hauser, Shigeyoshi Obata, Günter Eich, Zhao Zhentao oder Léon d'Hervey Marquis de Saint-Denys, der seine Tage anscheinend bevorzugt mit Lyrik und Wein verbrachte ${ }^{23}$ und 1862 womöglich als erster das Gedicht in Europa

21 Vgl. Sextus Empiricus: Grundriss der pyrrhonischen Skepsis, S. 122 (I, 124).

22 Für die Übersetzung sowie den Hinweis herzlichen Dank an Marc Winter.

23 Vgl. Pauline Yu: Judith Gautier and the Invention of Chinese Poetry, in: Reading Medieval Chinese Poetry. Text, Context, and Culture, hg. von Paul W. Kroll, Leiden: Brill, 2015 (Sinica Leidensia, Bd. 117), S. 251-288, hier S. 257. 
veröffentlichte. ${ }^{24}$ Leider fügte der Marquis noch einen anonymen Kommentar hin$\mathrm{zu}$, der wohl eine unschöne Wirkung hatte und später Judith Gautier und viele weitere dazu ermutigte, allerlei Bilder, die in das leere Gedicht hineingedeutet werden, in ihre Nachdichtungen zu übernehmen. Der Reif verweise auf den Tagesanbruch und den Augenblick des Aufbrechens. Dies könne nur der Gedanke eines Wanderers sein, der erwache - freilich ein Gedanke, der nirgends vorkommt. Aus der Ferne denke das Subjekt an seine Heimat, was traurig sei, und dergleichen mehr wird im Kommentar behauptet. ${ }^{25}$ Bei Gautier lautet der Titel folglich "L'Auberge«, und die Gedanken in stiller Nacht verschwinden. Stattdessen wird von neuen Ländern und fremden Menschen, denen man später begegnen soll, geträumt, von Freunden, die man nicht mehr sehen wird. ${ }^{26}$ Kalt sind die Mondstrahlen bei Launcelot Cranmer-Byng, warum bleibt unklar, und das Subjekt sinkt pathetisch »to dreams of thee - My Fatherland, of thee «. ${ }^{27}$ Noch kitschiger erklingt der letzte Vers bei Otto Julius Bierbaum (»Mein Haupt ich senke / Und dein gedenke / Ich, Dorf, du kleine Heimat mein $\ll),{ }^{28}$ beim rätoromanischen Dichter Peider Lansel, der von brennenden Herzen und Heimweh fantasiert (und dabei die gesamte antithetische Struktur weglässt), ${ }^{29}$ bei Xu Yuanchong, wo das Subjekt gar in Heimweh ertrinkt ${ }^{30}$ oder Hans Bethge, in dessen Version die Heimat wie ein Automat zuwinkt. ${ }^{31}$ Das Erkennen des Mondes im dritten Vers wird von Bethge (und auch von Jerome P. Seaton und James Cryer $^{32}$ ) - zumal das Subjekt eben noch an seiner Sinneswahrnehmung

24 Vgl. Hans Heilmann: Chinesische Lyrik vom 12. Jahrhundert v. Chr. bis in unsere Gegenwart, München: Piper, 1905; Otto Hauser: Gedichte aus dem Chinesischen. Metrische Übertragungen, Großenhain: Baumert \& Ronge, 1906; Li Bai: The Works of Li Po, übers. von Shigeyoshi Obata, London: J. M. Dent \& Sons, 1923; Günter Eich, zitiert in: Von Kaiser zu Kaiser. Klassische chinesische Lyrik und Kunstprosa von der Han-Zeit bis zur Song-Zeit. Eine Anthologie, hg. von Eva Schestag und Olga Barrio Jiménez, Frankfurt am Main: S. Fischer, 2009, S. 150; Zhao Zhentao, zitiert in: Miao Gao: An Analysis of Cultural Untranslatability, S. 350; Léon d'Hervey de Saint-Denys: Poésies de l'Époque des Thang, Paris: Amyot, 1862.

25 Vgl. d'Hervey de Saint-Denys: Poésies de l'Époque des Thang, S. 44f.; Forke: Blüthen chinesischer Dichtung, S. 145 f.

26 Vgl. Judith Gautier [Pseudonym: Judith Walter]: Le livre de jade, Paris: Alphonse Lemerre, 1867.

27 Vgl. Launcelot Cranmer-Byng: A Lute of Jade, Being Selections from the Classical Poets of China, London: John Murray, 1926 ['1909], S. $61 \mathrm{f}$.

28 Otto Julius Bierbaum: Irrgarten der Liebe. Verliebte, launenhafte und moralische Lieder, Gedichte und Sprüche aus den Jahren 1885 bis 1900, Berlin/Leipzig: Insel, 1901, S. 388, vgl. auch Weijian Liu: Kulturelle Exklusion und Identitätsentgrenzung. Zur Darstellung Chinas in der deutschen Literatur 1870-1930, Bern: Peter Lang, 2007 (Deutsch-Ostasiatische Studien zur interkulturellen Literaturwissenschaft, Bd. 7), S. 346.

29 Vgl. Peider Lansel: Poesias originalas e versiuns poeticas, hg. von Andri Peer, Samedan: Ediziun da l'Uniun dals Grischs e da la Lia Rumantscha, 1966 (Ouvras da Peider Lansel, Bd. 1), S. 225.

30 Vgl. Li Bai: Selected Poems, hg. von Yang Mushi, übers. von Xu Yuanchong, Changsha: Hunan People's Publishing House, 2007, S. 35.

31 Hans Bethge: Die chinesische Flöte, Leipzig: Insel 1919 ['1907], S. 36.

32 Vgl. Jerome P. Seaton/James Cryer: Bright Moon, Perching Bird. Poems by Li Po and Tu Fu, Middletown: Wesleyan University Press, 1987, S. 27. 
zweifelte - besonders betont, was in einigen Jing ye si-Vertonungen zu absurden Stellen führte: »Dann aber wusste ich: der Mond, der Mond... «. ${ }^{33}$ Man fragt sich, was nach dieser Logik genau erkannt wurde. Klabund ersetzte das Wort Heimat durch »mein Wanderziel «. ${ }^{34}$ Als Erwiderung auf eine entsprechende Kritik von Robert Neumann wies er auf einen anonymen chinesischen Kommentar hin, wohl jenen bei Léon d'Hervey de Saint-Denys. ${ }^{35}$ Andere verengten das Originalgedicht mit selbsterzeugten Bildern der Objekte. Bei Günter Eich ist das Mondlicht nicht mehr hell, ohne Angabe einer bestimmten Farbe, sondern weiß ${ }^{36}$ (so wie bei Forke Schnee statt Reif erscheint), bei Richard Dehmel wird aus dem potenziell unendlichen und undefinierten Boden eine Diele mit Schwelle, ${ }^{37}$ und bei Witter Bynner trägt das unbekannte Bett plötzlich Füße, und senkt sich nicht ein Kopf, sondern ein $»$ myself $« .{ }^{38}$ All jene Nachdichter ${ }^{*}$ innen haben leere Erscheinungen mit eigenen Bildern ersetzt. Noch weiter gingen Komponist ${ }^{*}$ innen.

\section{Gedanken über einzelne Vertonungen des Jing ye si ${ }^{39}$}

Ungefähr jede sechste Li-Bai-Vertonung im Westen ist eine des Jing ye si. ${ }^{40}$ Nur das Gedicht In einer Frühlingsnacht in Luoyang eine Flöte hören (Chun ye Luo cheng wen

33 Vgl. Bethge: Die chinesische Flöte, S. 36.

34 Vgl. Klabund: Li Tai Pe. Nachdichtungen, Leipzig: Insel, 1915, S. 20.

35 Vgl. Kuei-Fen Pan-Hsu:Die Bedeutung der chinesischen Literatur in den Werken Klabunds. Eine Untersuchung zur Entstehung der Nachdichtungen und deren Stellung im Gesamtwerk, Frankfurt am Main: Peter Lang, 1990 (Europäische Hochschulschriften, Reihe I: Deutsche Sprache und Literatur, Bd. 1179), S. 71; Robert Neumann: Li Tai Po. Ein deutscher Dichter, in: Die Neue Bücherschau 6 (1928), S. 77-81.

36 Vgl. Schestag/Barrio Jiménez: Von Kaiser zu Kaiser, S. 150.

37 Vgl. Richard Dehmel, zitiert nach Tzu-Kuang Chen: Chinesische Kultur in der westlichen Musik des 20. Jahrhunderts, Frankfurt am Main: Peter Lang, 2006 (Europäische Hochschulschriften, Reihe XXXVI: Musikwissenschaft, Bd. 243), S. 136.

38 Vgl. Witter Bynner, zitiert nach Chingshuan Lily Hsieh: Chinese Poetry of Li Po Set by Four Twentieth Century British Composers. Bantock, Warlock, Bliss and Lambert, Diss. Ohio State University, 2004, S. 11.

39 Für hilfreiche Diskussionen zu den Vertonungen bedanke ich mich herzlich bei Roman Brotbeck und vor allem bei Damian Elmer.

40 Vgl. die Liste unter www.hkb-interpretation.ch/li-bai: Othmar Schoeck (1907), Hubert Pataky (1911), Gena Branscombe (1911), James Simon (1913), C. H. van der Leeuw (1913), Bernard van Dieren (1913), Martin Spanjaard (1916), Eberhard Waechter (1916), Anton Webern (1917), Bohuslav Martinů (1918), Hanns Eisler (1919), Anton Lajovic (1920?), James Lyon (1922), Wilhelm Rettich (1922), Hans Apostel (1923), Walther Hensel (1925), Leo Michielsen (1930), Emil Staiger (1930), Henri Enthoven (1930?), Volkmar Andreae (1931), Anton Würz (1932), Ernst Tittel (1934), Josef Eduard Ploner (1935), Jean Robert Blanc (1939), Max Ettinger (1939), Viktor Ullmann (1943), Dietrich Erdmann (1945), Seppo Nummi (1945), Gottfried von Einem (1946), Raymond Wilding-White (1951), Ezra Sims (1954), Hanning Schröder (1958), Arno Stepanian (1959), Franz Biebl (1963), Denise Roger (1965 und 2003), Martin Gümbel (1966), Viktor Ussowitsch (1974), Robert Schollum (1979), Tolegen Mukhamedzhanov (1980?), Marcel 
$d i$ 春夜洛城闻笛) wurde noch häufiger in Musik gesetzt. ${ }^{41}$ Werfen wir kurz einen Blick auf sieben Jing ye si-Vertonungen, jene von Othmar Schoeck (1907), James Simon (1913), Walther Hensel (1925), Volkmar Andreae (1931), Viktor Ullmann (1943), Gottfried von Einem (1946) und Lawrence Moss (1999), sowie einen Nebenblick auf jene von Anton Webern (1917), David McMullin (1999) und Krzysztof Penderecki (2017).

Othmar Schoeck fand in Leipzig - er studierte dort bei Max Reger - die Anthologie chinesischer Gedichte von Hans Heilmann, worauf er das Jing ye si vertonte und im Juni 1907 seinen Eltern mitteilte: »In letzter Zeit bin ich ein halber Chinese geworden [...]. Ihr ahnt es nicht, was das für feine Kerle sind! «. ${ }^{42} \mathrm{Zu}$ den ersten beiden Versen erklingt im Klavier ein melodisch wie auch harmonisch zirkulierender Klang, der sich sanft von einem Ausgangspunkt entfernt und wieder zurückkehrt. ${ }^{43}$ Die Harmonien sind in h- und e-Moll, aber die Melodie hat einen modalen (äolischen) Charakter. Die Klavierstimme des ersten Verses wird im zweiten Vers wiederholt, doch um eine Quarte erhöht. Gleichzeitig sinkt die Gesangsstimme im zweiten Vers, wo Reif wahrgenommen zu werden scheint, in Quinten. So scheint die wirkliche Raumtemperatur, jene des ersten Verses, erhalten zu bleiben: die Klavierstimme mag durch die höhere Lage wärmer erscheinen, die Gesangsstimme durch die fallenden Quinten aber kälter, wodurch sich die Kälte des Reifes als Illusion des Subjekts zeigt (Abbildung 1). Auch der dritte Vers wurde, nun durch den Wechsel von Dur- und Moll-Akkorden, sanft und unbestimmt in Klang gesetzt. Das Senken des Hauptes im vierten Vers wird in der Gesangsstimme durch eine absteigende Klagefigur dargestellt - wie bei den meisten Vertonungen, ${ }^{44}$ bei Krzysztof Penderecki gar mit einem Passus duriusculus ${ }^{45}$ - und dann als (psychisches) Echo (der Handlung) im Klavier wiederholt. Wenig später erscheint nach Modulationen von Moll-Klängen in Takt 16 die Tonika in H-Dur, sozusagen als Heimat. Diese wird anschließend musikalisch in einer Coda präsentiert, auch dies ein Charakteristikum vieler Jing ye si-Vertonungen. Bei Anton Webern erklingen in der Coda Celesta und Harfe, bei Volkmar Andreae eine Englischhornmelodie sowie ein Gong und bei Penderecki Hörner aus der Ferne. In Schoecks Coda befindet sich ein Fragment des

Rubin (1987), David McMullin (1999), Lawrence Moss (1999), Jan Krzywicki (2003), Bruno Gousset (2004), Robert Zollitsch (2006), Krzysztof Penderecki (2017).

41 Vgl. den Beitrag »Quantitative Überlegungen zum Phänomen der Li-Bai-Vertonungen im Westen« des Autors in diesem Band, S. 219-239.

42 Vgl. Werner Vogel: Othmar Schoeck. Leben und Schaffen im Spiegel von Selbstzeugnissen und Zeitgenossenberichten, Zürich: Atlantis, 1976, S. 54.

43 Vgl. Derick Puffet: The Song Cycles of Othmar Schoeck, Bern: Paul Haupt, 1982 (Publikationen der Schweizerischen Musikforschenden Gesellschaft, Bd. 32), S. $110 \mathrm{f}$.

44 Bei allen untersuchten Vertonungen mit Ausnahme jener von Viktor Ullmann, Gottfried von Einem und David McMullin. Eine in Halbtönen abgetragene Quarte als Stilmittel der Trauermusik. 
pentatonischen Jasminblüten-Liedes Mo Li Hua 茉莉花, ${ }^{46}$ die Heimat wäre demnach im erträumten China zu verorten. Weil die Textvertonung von Schoeck mit einem Terzsprung auf das Wort >Bett ` (Takt 2) beginnt und mit derselben Intervallgruppe beim Wort `Heimatland` (Takt 16) endet, mag das Subjekt im Bett von seiner Heimat träumen (also nicht an sie denken), ähnlich wie in den Übertragungen von Gautier oder Cranmer-Byng.

\section{In der Herberge.}
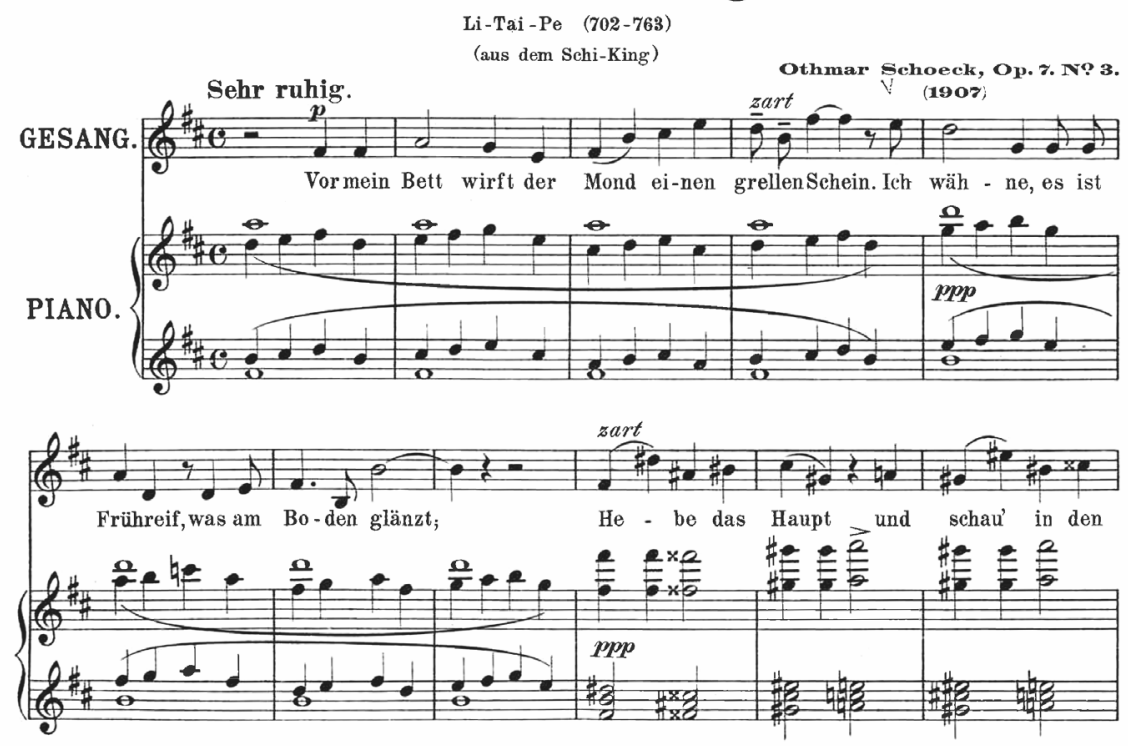

Abb. 1: Zirkulierende Klänge in Othmar Schoecks In der Herberge, 1907

Nicht verträumt-unbestimmt wie bei Schoeck, hingegen eher dramatisch, frei von musikalischen Exotismen, erklingt die Vertonung von James Simon. Passend dazu, womöglich durch die Vergangenheitsform in der verwendeten Nachdichtung von Bethge verursacht, scheint ein Maulheld seine Geschichte zu erzählen, deren Sinn niemand versteht. Das Mondlicht glitzert in den hohen Registern des Klaviers, der Textvortrag wird durch aufwärtsstrebende Instrumentalgesten und harmonische Akkordumdeutungen eingeleitet und weitergetrieben und die ferne Heimat rhythmisch verlangsamt und mit einem aufgesetzten Aufstieg nach C-Dur erreicht (Abbildung 2).

Die Verwendung von Verklärungen in Dur beim letzten Heimatvers ist bei vielen Jing ye si-Vertonungen anzutreffen. Selbst in jener von David McMullin, bei wel-

46 Zu diesem Lied, das später auch von Giacomo Puccini in Turandot oder Harry Partch in On Hearing the Flute in the Yellow Crane House (Seventeen Lyrics by Li Po) zitiert wurde, siehe Chen: Chinesische Kultur in der westlichen Musik des 20. Jahrhunderts, S. 67-89. 

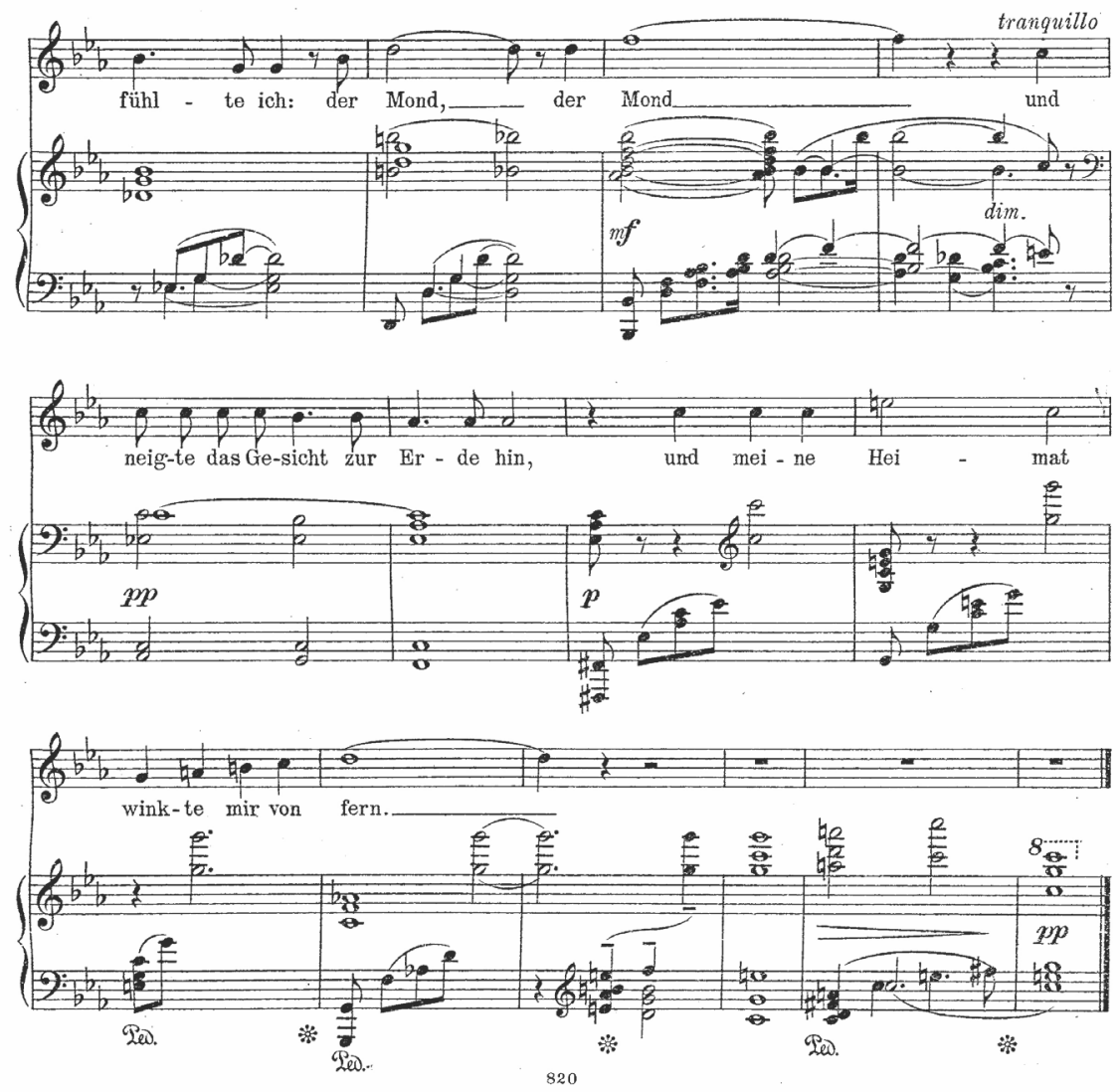

Abb. 2: Drama in James Simons In der Fremde, 1913

cher der chinesische Text ausschließlich von einem $a$ der Violine begleitet wird in den ersten beiden Versen als Flageolett, dann gewöhnlich gestrichen - sinkt die Stimme der Violine ganz am Schluss bei $g u$ 故 um einen Halbton und bildet dadurch bei Heimat (xiang 鄉) zusammen mit der Gesangsstimme einen Dur-Akkord.

Grotesk, weil die Musik nicht zum Nonsense des Textes passt, wirkt Simons Dramatik, etwa durch die Verwendung punktierter Rhythmen, beim Textabschnitt »dann aber fühlte ich: der Mond, der Mond « (Abbildung 2). Dies ist bei anderen Vertonungen von Bethges Nachdichtung nicht anders, etwa bei Gottfried von Einem, wo die statische Gesangsstimme gerade bei dieser Textstelle Bewegung aufnimmt, oder bei Penderecki, wo sich plötzlich Glockenspiel und Celesta in Sexten abwechseln. Anton Webern scheint Bethges Satz sarkastisch, ja zynisch kommentiert zu haben. Der Mond, der Mond erklingt nur leise und kurz in kleinen Terzen, nebensächlich und verschwindend. Dann folgt als überraschender Kontrast in den Streichinstrumenten ein gemeinsam gespieltes Flageolett in maximaler Lautstärke (Abbildung 3). Vielleicht ist die Geste - vermittelt über die bedrohliche "Enthauptung« durch den »Mond, ein blankes Türkenschwert« im dreizehnten Satz aus 
Arnold Schönbergs Pierrot Lunaire - eine Allusion an das Fallbeil der Guillotine im vierten Satz aus Berlioz' Symphonie fantastique. ${ }^{47}$ Nach dem Flageolett-Fallbeil neigt das Subjekt bei Webern seinen Kopf zur Erde hin.

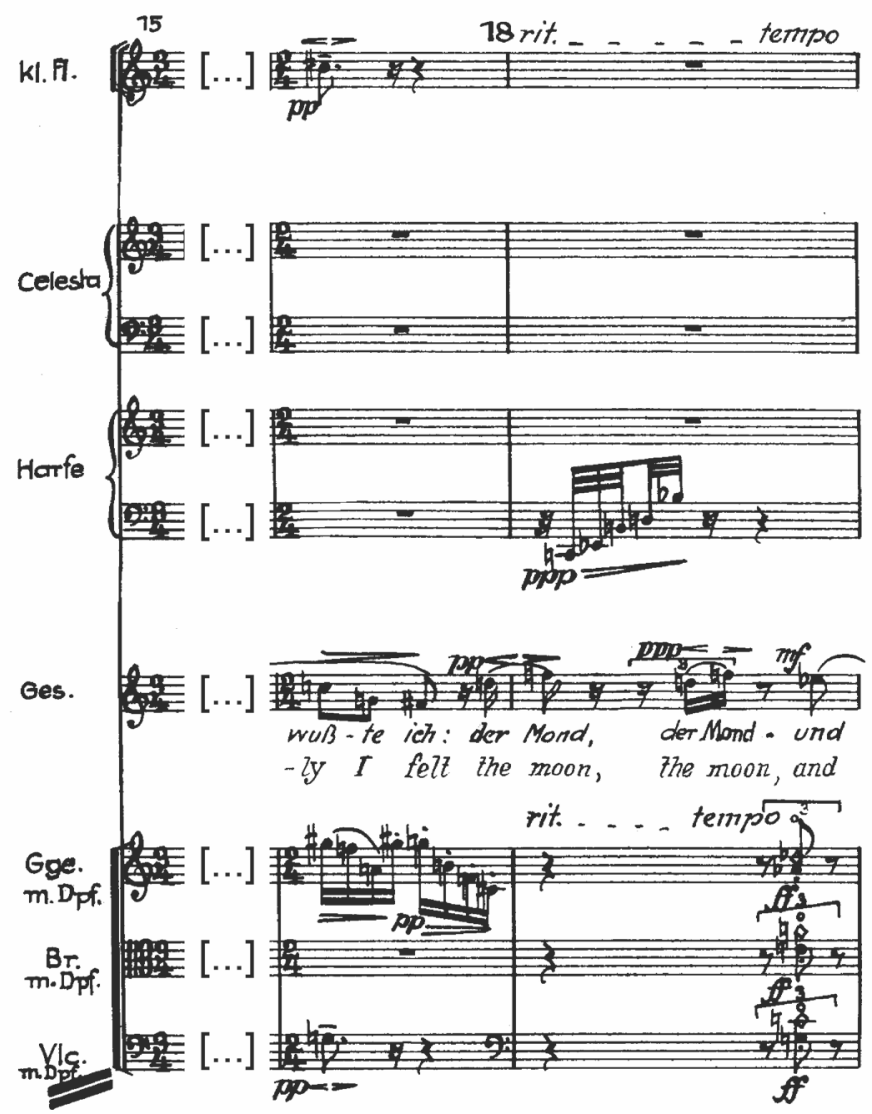

Abb. 3: Sarkastischer Kommentar in Anton Weberns In der Fremde, 1917

47 Webern hörte Berlioz' Symphonie fantastique, gespielt vom Kaim-Orchester unter der Leitung von Felix Weingartner, am 5. Januar 1903 in Wien und bezeichnete das Werk in einem Brief vom 18. Februar 1903 an Ernst Diez als »kolossal«. Ein Brief von Webern an Heinrich Jalowetz vom 30. Juni 1905 zeugt zudem von seiner Begeisterung für die Berlioz-Strauss'sche Instrumentationslehre, siehe Anton Webern: Briefe an Heinrich Jalowetz, hg. von Ernst Lichtenhahn, Mainz: Schott, 1999, S. 111. Für die Literaturhinweise bedanke ich mich herzlich bei Matthias Schmidt. Wenn die Mond-Geste bei Webern auf Berlioz' Symphonie fantastique anspielen sollte, dann könnten die darauffolgenden Tremoli und Triller der Klarinette, Violine und des Cellos im Pianissimo in den Takten 19 bis 20 als sarkastische Varianten des Geschreis der Menschenmenge beim Schafott in Paris gehört werden. 
Die Jing ye si-Vertonung von Walther Hensel, als Teil eines Zyklus mit Mondliedern, mag in ihrer Absicht ähnlich dramatisch sein wie Simons Version - mit zusätzlichen Melismen beim letzten Heimatvers -, ist im Ausdruck und der Struktur aber nicht mit dem Metier des Letzteren zu vergleichen. Mit vielen Wiederholungen, ungeachtet des Textinhaltes und fast ohne Modulationen, hie und da mit kleinen kontrapunktischen Stellen erweitert, klimpert das Lied in stiller Nacht. Auf die Wandervogelbewegung und Hitlerjugend verweist die Besetzung für Stimme, Flöten und Lauten. ${ }^{48}$ Hensel komponierte zahlreiche nationalsozialistische Arbeiterund Kriegslieder ${ }^{49}$ und war als früher Organisator von Singwochen ein Vorbild für den sogenannten »Sing- und Spielschar«-Unterricht der NS-Zeit ${ }^{50}$ - von Gitarre und Blockflöten begleitet, wurden einstimmig Nazilieder gesungen.

Eher bleiern-statisch wirkt dann die Orchesterfassung von Volkmar Andreae. Grund ist die Gesangsstimme mit ihren vielen syllabischen Rhythmus- und Tonwie-

\section{Nọ 2. Wanderer erwacht in der Herberge}
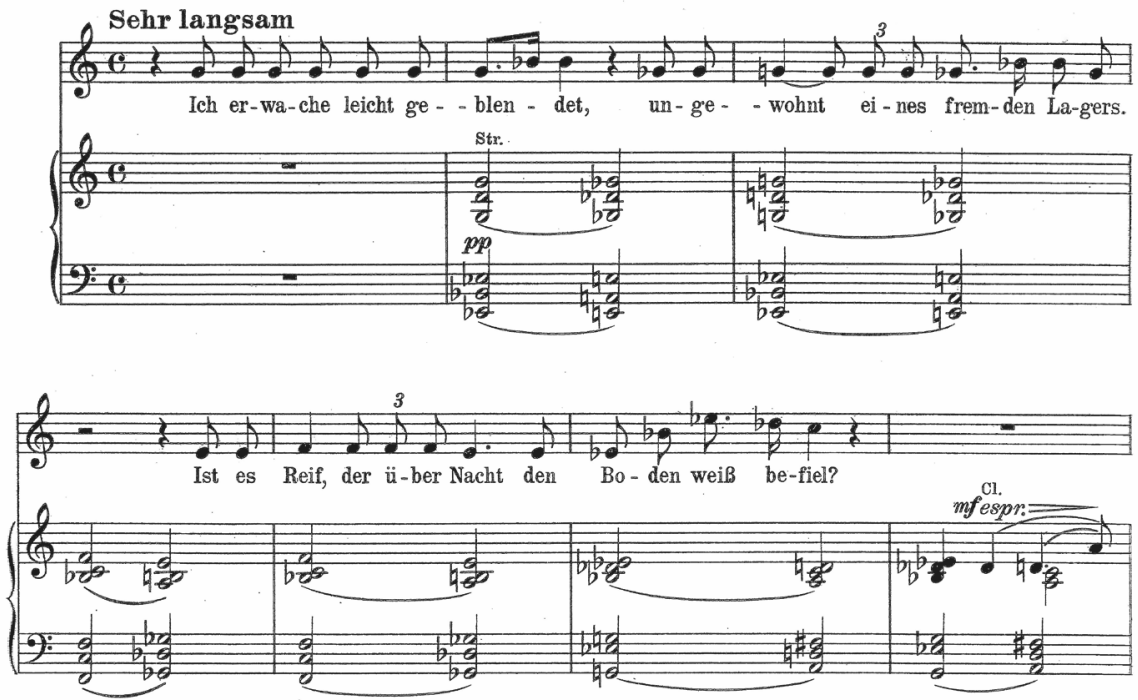

Abb. 4: Bleiern-statische Klänge in Volkmar Andreaes

Wanderer erwacht in der Herberge, 1931 (Klavierauszug)

48 Vgl. Markus Zepf: Musik bewegt. Zu Lied und Musik der Jugend- und Singbewegung bis zum Zweiten Weltkrieg, in: Aufbruch der Jugend. Deutsche Jugendbewegung zwischen Selbstbestimmung und Verführung, hg. von Claudia Selheim, G. Ulrich Großmann und Barbara Stambolis, Nürnberg: Germanisches Nationalmuseum, 2013, S. 67-72.

49 Vgl. Fred K. Prieberg: Handbuch Deutsche Musiker 1933-45, Selbstverlag, 2009, online, Kapitel »Walther Hensel«.

50 Vgl. Christian Wolf: Musikerziehung unterm Hakenkreuz. Die Rolle der Musik am Beispiel der Oberschulen im Gau Tirol-Vorarlberg, Anif/Salzburg: Müller-Speiser, 1998 (Innsbrucker Hochschulschriften, Serie A: Musikpädagogik, Bd. 3), S. 68, 109, 268-278. 
derholungen sowie kleinem Tonumfang (der das Sprechhafte verstärkt), ferner die gehaltenen Orchester-Akkorde, die sich minimal verschieben und wieder zur selben Gestalt zurückkehren, somit ähnlich wie bei Schoecks Vertonung zirkulieren. Weil sich zwischen zwei Akkorden die oberste und unterste Stimme - oder auch andere Stimmen - entgegengesetzt bewegen, die eine einen Halbton abwärts, die andere aufwärts, teils auch wegen sanfter, ausgehaltener Dissonanzen (beispielsweise eine verminderte Tredezime in der Gesangsstimme über einem C-Dur-Klang des Orchesters beim sstrahlenden Mond $)$, vibriert das Statische leicht. Die vier Verse werden musikalisch nicht groß gedeutet und unterschieden.

Klagend, manchmal schmerzhaft klingt die Jing ye si-Vertonung von Viktor Ullmann, die in Geste und Ausdruck stark an Hanns Eislers Jing ye si-Version von 1919 erinnert. Die Heimat beziehungsweise das Wanderziel, da Ullmann Klabunds Nachdichtung verwendet, wird bei ihm nicht mehr in Dur verklärt, sondern erscheint stattdessen als unangenehm-dissonanter Akkord (Es-Dur vermischt mit h-Moll und übermäßiger Quinte) auf dem tiefsten Ton der Melodie. Außerdem bewegt sich die Gesangsstimme bei »neige das Haupt « schreiend, trotzartig nach oben (Abbildung 5), und verzichtete Ullmann überdies auf den dritten Vers (»Hebe das Haupt - blick in den strahlenden Mond «). ${ }^{51}$ Er vertonte das Gedicht von Li Bai - so wie Pavel Haas in seinen Vier Lieder nach Worten chinesischer Poesie Gedichte von Wang Wei 王維 (699/701-759/761) und anderen chinesischen Lyrikern - im KZ Theresienstadt. Die Bücher fanden sie bei Mitgefangenen oder in der sogenannten Ghettozentralbücherei. ${ }^{52}$ In Theresienstadt war das organisierte Spielen von Musik, auch jüdischer, erlaubt, teils um das Lager nach außen als liberales Zentrum der Kultur zu propagieren, teils um das Verdrängen der Situation durch Kunst zu unterstützen und mögliche Aufstände zu vermeiden. ${ }^{53}$ Beinahe alle Eingesperrten - das Lager diente als Durchgangslager - wurden später in Vernichtungslagern ermordet. ${ }^{54}$ Die chinesischen Lieder von Haas erklangen in Theresienstadt kurz vor dessen Deportation im Herbst 1944 nach Auschwitz. Simon Laks, Leiter des Männerorchesters im KZ Auschwitz, beschreibt in seiner Autobiografie die Ankunft des >Tschechischen Lagers` aus Theresienstadt. Sie hatten ein kleines Musikensemble und wurden wenige Tage später alle in den Gaskammern umgebracht. Die Musikinstrumente kamen darauf in Besitz des Auschwitz-Orchesters. ${ }^{55}$ Ferner verweist Laks, nebenbei

51 Vgl. Cynthia L. Smith: »Hallo, Hallo! Achtung! Achtung!... «. A Performer's Guide to the Theresienstadt Compositions of Viktor Ullmann for the Mezzo-Soprano, Diss. Ball State University, Muncie, IN, 2014, S. 72 f.; Klabund: Li Tai Pe, S. 20.

52 Vgl. Smith: Hallo, Hallo! Achtung! Achtung!, S. 64 f.; Lubomír Peduzzi: Musik im Ghetto Theresienstadt. Kritische Studien, Brno: Barrister \& Principal, 2005, S. $91 \mathrm{f}$.

53 Vgl. Smith: Hallo, Hallo! Achtung! Achtung!, S. 27 f.

54 Nach Theresienstadt wurden mehr als 141'000 Menschen deportiert, ca. 88'000 - so wie Ullmann oder Haas - von dort weiterdeportiert und in Vernichtungslagern umgebracht, $30^{\prime} 000$ starben bereits in Theresienstadt, vgl. Ingo Schultz: Viktor Ullmann. Leben und Werk, Kassel: Bärenreiter, 2008, S. 227.

55 Vgl. Simon Laks: Musik in Auschwitz, übers. von Mirka und Karlheinz Machel, Berlin: Boosey \& Hawkes, 2014, S. $93 \mathrm{f}$. 
erwähnt, auf die demoralisierende und zynische Wirkung der Musik. Ihm und anderen Orchesterspieler*innen mag die Musik das Leben gerettet haben, für alle anderen Mitgefangenen hingegen war sie, gespielt, während sie gefoltert und ermordet wurden, eine Qual und »vertiefte noch den chronischen Zustand ihrer physischen und psychischen Entkräftung « ${ }^{56}$ Durch fallende Halbtöne, steigende Septimen, verschobenen Phrasen oder unklares Metrum mag Ullmans Li-Bai-Vertonung Desorientiertheit und Schmerz ausdrücken. ${ }^{57}$ Die Musik ist nicht im klassischen Sinne tonal, hat aber ein tonales Zentrum, nämlich einen as-Moll-Akkord, der siebenmal erscheint (Takte 1, 9, 10, 18, 26, 28, 30). As-Moll mag, wie beim zweiten Refrain des Textes »Dunkel ist das Leben, dunkel ist der Tod « im ersten Lied aus Gustav Mahlers Lied von der Erde, auf Ferne, Verlorenheit und Trauer verweisen, ${ }^{58}$ die Zahl 7 gemäß Zahlensymbolik, so wie die Septime, auf Bedrohung. ${ }^{59}$ Ebenfalls siebenmal erscheint in Ullmanns Musik ein Motiv samt Varianten, das erstmals beim Wort `Reif erklingt, sozusagen ein $>$ Reif $\triangleleft$-Motiv (Takte 9, 10, 12, 13, 18, 19, [20], 28). Dieses Motiv, auch im drittletzten Takt das Ende des Liedes einleitend, besteht aus den Tönen
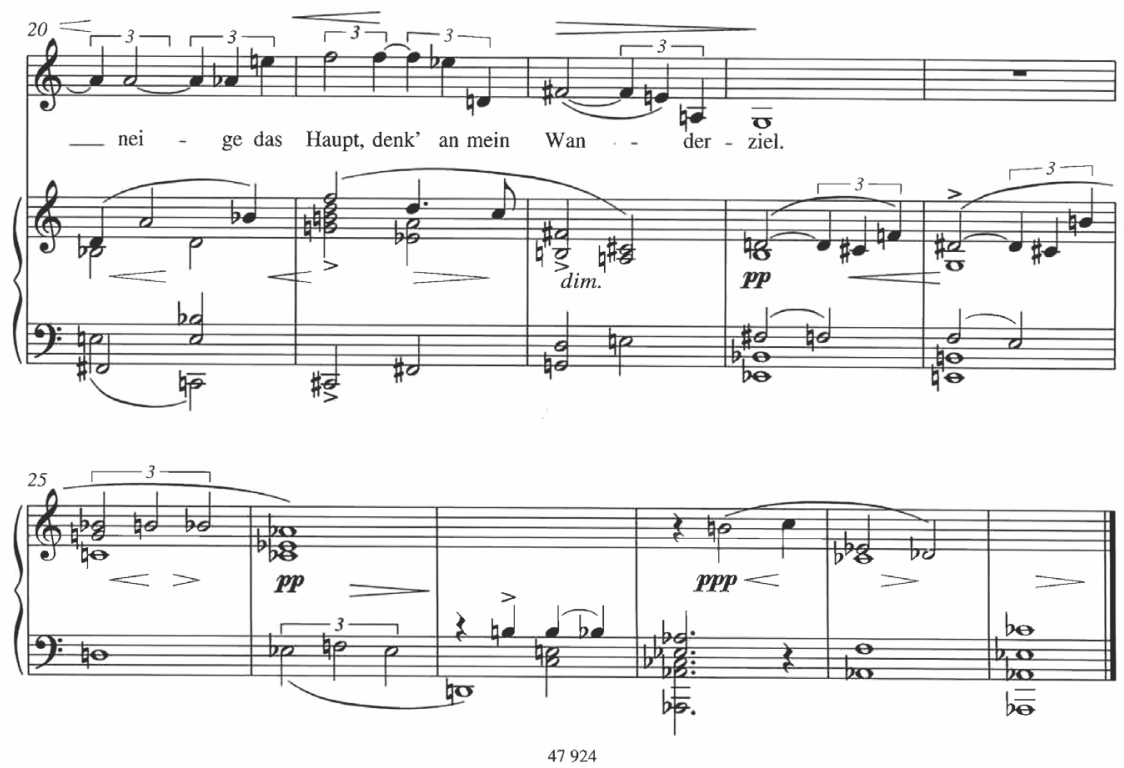

Abb. 5: Bedrohung und Schmerz in Viktor Ullmanns Wanderer erwacht in der Herberge, 1943

Vgl. ebd., S. 16, 118 f., 121.

Vgl. Smith: Hallo, Hallo! Achtung! Achtung!, S. 66-68.

58 Vgl. Silja Haller: Wort-Ton-Gestaltung in der Sinfonik Gustav Mahlers, Potsdam: Universitätsverlag Potsdam, 2012, S. 253.

Vgl. Schultz: Viktor Ullmann, S. 183. 
$h$-c, gefolgt von einem as-Moll-Akkord as-ces-es. Die Tonnamen des Motivs mögen ein Anagramm bilden, und die Aussage lautet a(u)sch(w)e(t)s, also Auschwitz (Abbildung 5, Takte 28/29, hier ergänzt mit f).$^{60}$ Ullmann wusste, wohin die Reisen aus Theresienstadt führten.

Man stelle sich bloß die Lebensläufe der Komponist*innen vor, die Li Bais Jing ye si vertonten: Marcel Rubin wurde in die KZ von Meslay-du-Maine und Rennes deportiert, schaffte es aber, nach Mexiko zu fliehen, drei andere Komponisten wurden im KZ Auschwitz ermordet, nämlich Ullmann, James Simon, der es vielleicht sorglos vorzog, in einer deutschsprachigen Kultur zu leben (und selbst noch im KZ Theresienstadt über deutsche Komponisten Vorträge hielt), ${ }^{61}$ sowie Martin Spanjaard, ehemaliger Assistent von Willem Mengelberg. Gleichzeitig finden wir unter den Jing ye si-Vertonern Nazis und NSDAP-Mitglieder wie den erwähnten Walther Hensel, zudem Hubert Pataky, Anton Würz, Josef Eduard Ploner, sozusagen Hofkomponist des Gauleiters Franz Hofer in Innsbruck, ${ }^{62}$ Franz Biebl oder Robert Schollum, der später noch ein Buch über die Musik des jüdischen Komponisten und Li-Bai-Vertoners Egon Wellesz schrieb. ${ }^{63}$ Ein Jahr nach dem Ende der Katastrophe vertonte Gottfried von Einem dasselbe Gedicht wie Ullmann. Die Gesangsstimme in von Einems Version besteht aus lang andauernden Wiederholungen desselben, beinahe erstarrten Tons ${ }^{64}$ (wie zum Teil auch in Franz Schuberts "Der Wegweiser" aus der Winterreise zu hören). Das Lied endet in einer leeren Oktave, und in den beiden Stimmen des Klaviers erklingen - neben Seufzermotiven, verdichtet im Mittelteil - zwei Themen in langer und asymmetrischer Phrasierung, also von konfuser Wirkung, die teils zudem noch imitiert (Abbildung 6) oder übereinandergeschichtet werden.

60 Im fünften Satz der fünften Klaviersonate von Ullmann verweisen die Tonnamen des Themas auf das Wort »Theresienstadt«. Vgl. Schultz: Viktor Ullmann, S. 207. Das Motiv am Anfang des Liedes, in der zweiten Hälfte des zweiten Taktes, mit der steigenden kleinen Terz und der fallenden Septime, verwendete Ullmann bereits 1936 im zweiten Satz seiner ersten Klaviersonate, Gustav Mahler gewidmet. Vgl. Smith: Hallo, Hallo! Achtung! Achtung!, S. 67.

61 Vgl. Philipp Silver/Carine Alder: James Simon, online, [o. J.], www.forbiddenmusicregained. org/search/composer/id/102025 (Zugriff 20.03.2020).

62 Vgl. Wolf: Musikerziehung unterm Hakenkreuz, S. 146f.; für das Thema Komponisten in NSZeit immer Prieberg: Handbuch Deutsche Musiker 1933-45. Dem Nationalsozialismus zumindest nicht abgeneigt waren auch die Jing ye si-Vertoner Anton Webern und Othmar Schoeck.

63 Vgl. Egon Wellesz/Emmy Wellesz: Egon Wellesz. Leben und Werk, hg. von Franz Endler, Wien: Paul Zsolnay, 1981, S. 80 und 267. Wellesz wusste vermutlich nichts von Schollums NS-Zeit und war erstens stolz, dass ein Buch über ihn geschrieben wurde, zweitens wohl erfreut, einen Gesprächspartner gefunden zu haben, mit dem er gemeinsam gegen die Darmstadt-Szene polemisieren konnte. Vgl. auch Nina-Maria Wanek: Egon Wellesz in Selbstzeugnissen. Der Briefnachlass in der Österreichischen Nationalbibliothek, Wien: Österreichische Akademie der Wissenschaften, 2010 (Byzantina et Neograeca Vindobonensia, Bd. 27), S. $106 \mathrm{f}$.

64 Vgl. Robert Schollum: Das österreichische Lied des 20. Jahrhunderts, Tutzing: Hans Schneider, 1977 (Publikationen des Instituts für Österreichische Musikdokumentation, Bd. 3), S. 153 f. 


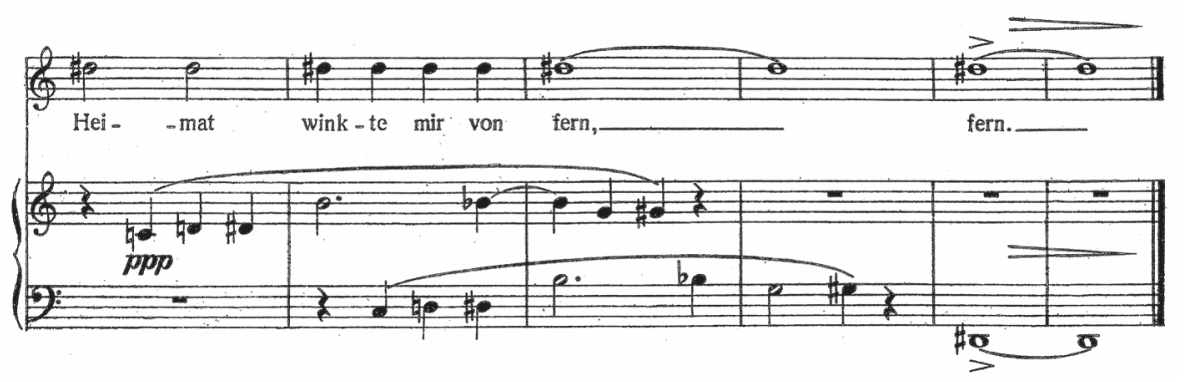

Abb. 6: Erstarrte Gesangsstimme in Gottfried von Einems In der Fremde, 1946

Erwähnt sei noch kurz die Jing ye si-Musik für Stimme und Cello von Lawrence Moss ${ }^{65}$ die manchmal klagend und seufzend - ähnlich wie die von Ullmann oder von Einem - zu erklingen scheint, dann auch theatralisch wie die von Simon. Als Text verwendete Moss eine eigene Version, die wie folgt lautet: »Ah...Hmm... Ah...Before my bed bright moonlight...Ah...Ah [...] Look up...eyes see the moon bright,...Look down...Ah...Heart...Heart mourns...heart mourns...home...lost ah...«. Als Trauerfiguren treten reibende Intervalle wie Septimen, Nonen oder Dezimen, die oft in Form von Glissandi ausgeführt werden, Tritonusparallelen oder in Takt 37 eine Aposiopesis auf. ${ }^{66}$ Theatralische (womöglich auch ironische) Elemente wären neben entsprechenden Spielanleitungen wie am Anfang »The Cellist and Singer [...] gaze out over the audience if seeing something in the distance « vor allem die vielen Ah-Seufzer sowie die Darstellung von Glanz durch schnelle und hohe Flageolettfolgen oder Frost durch Quinten-Pizzicati im Cello; als exotische Elemente finden sich Ganztonfolgen.

Schoeck hat eine träumerische Version des Jing ye si komponiert, Simon eine dramatische, Hensel eine wandervogelartige, Andreae eine statische, Ullmann eine

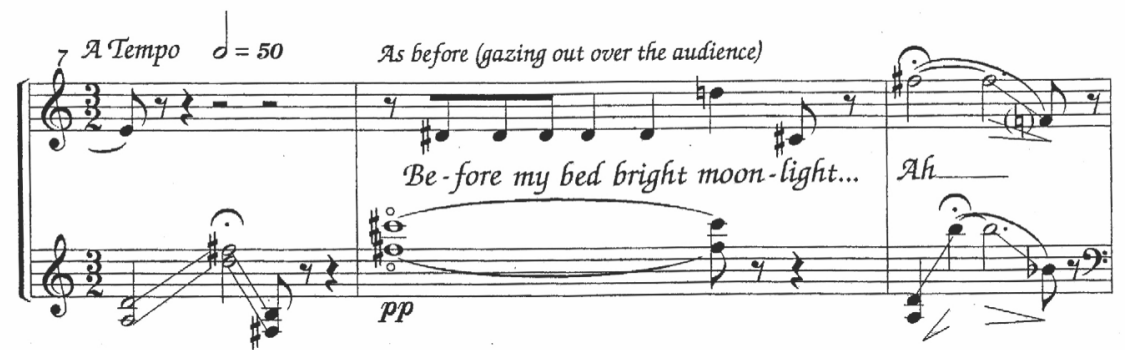

Abb. 7: Theatralische Klagen in Lawrence Moss' Three Chinese Poems Nr. 3, 1999.

65 Für die Zusendung der Partitur von Silver Spring nach Samedan bedanke ich mich herzlich beim Komponisten.

66 Aposiopesis = eine Generalpause als Ausdruck des Verstummens. 
schmerzhafte, von Einem eine erstarrte, Moss eine theatralische. Sie alle haben mittels tradierter musikalischer Affektfiguren und unterschiedlicher Gestaltung von Rhythmik, Melodik und Harmonik Emotionen und Deutungen auf Notenpapier festgehalten. Das Gedicht von Li Bai aber war nur eine leere Erscheinung.

\section{Literatur}

Andreae, Volkmar: "Wanderer erwacht in der Herberge«, in: ders.: Li-Tai-Pe. Acht chinesische Gesänge für eine Tenorstimme und Orchester op. 37. Nachdichtungen von Klabund, Leipzig: Hug \& Co., 1931, S. 7 f.

Bethge, Hans: Die chinesische Flöte, Leipzig: Insel, 1919 [ [1907].

Bierbaum, Otto Julius: Irrgarten der Liebe. Verliebte, launenhafte und moralische Lieder, Gedichte und Sprüche aus den Jahren 1885 bis 1900, Berlin/Leipzig: Insel, 1901.

Chen, Tzu-Kuang: Chinesische Kultur in der westlichen Musik des 20. Jahrhunderts, Frankfurt am Main: Peter Lang, 2006 (Europäische Hochschulschriften, Reihe XXXVI: Musikwissenschaft, Bd. 243).

Cranmer-Byng, Launcelot: A Lute of Jade, Being Selections from the Classical Poets of China, London: John Murray, 1926 [ $\left.{ }^{1} 1909\right]$.

Diogenes Laertius: Leben und Meinungen berühmter Philosophen, übers. von Otto Apelt, hg. von Klaus Reich, Hamburg: Meiner, 2008.

Einem, Gottfried von: »In der Fremde«, in: ders.: Fünf Lieder aus dem Chinesischen für mittlere Singstimme und Klavier op. 8, Berlin: Bote \& Bock, 1950 ['1946], S. 4 f.

Forke, Alfred: Blüthen chinesischer Dichtung. Aus der Zeit der Han- und Sechs-Dynastie, Magdeburg: Faber, 1899.

Gautier, Judith [Pseudonym: Judith Walter]: Le livre de jade, Paris: Alphonse Lemerre, 1867.

Giegling, Franz: Volkmar Andreae, Zürich: Hug \& Co., 1959 (Neujahrsblatt der Allgemeinen Musikgesellschaft Zürich, Bd. 143).

Haller, Silja: Wort-Ton-Gestaltung in der Sinfonik Gustav Mahlers, Potsdam: Universitätsverlag Potsdam, 2012.

Hauser, Otto: Gedichte aus dem Chinesischen. Metrische Übertragungen, Großenhain: Baumert \& Ronge, 1906.

Heilmann, Hans: Chinesische Lyrik vom 12. Jahrhundert v. Chr. bis in unsere Gegenwart, München: Piper, 1905.

Hensel, Walther: »In stiller Nacht«, in: ders.: Das Silberhorn. Mondlieder für Gesang, Flöten und Lauten, Augsburg: Bärenreiter, 1925, S. 12-16.

d'Hervey de Saint-Denys, Léon: Poésies de l'Époque des Thang, Paris: Amyot, 1862.

Hsieh, Chingshuan Lily: Chinese Poetry of Li Po Set by Four Twentieth Century British Composers. Bantock, Warlock, Bliss and Lambert, Diss. Ohio State University, 2004.

Huang Po: Der Geist des Zen. Die legendären Aussprüche und Ansprachen des Huang-po, übers. von Ursula von Mangoldt, München: O. W. Barth, 2011.

Jones, Richard H.: The Heart of Buddhist Wisdom. Plain English Translations of the Heart Sutra, the Diamond-Cutter Sutra, and other Perfection of Wisdom Texts, New York: Jackson Square Books, 2012. 
Klabund: Li Tai Pe. Nachdichtungen, Leipzig: Insel, 1915.

Laks, Simon: Musik in Auschwitz, übers. von Mirka und Karlheinz Machel, Berlin: Boosey \& Hawkes, 2014.

Lansel, Peider: Poesias originalas e versiuns poeticas, hg. von Andri Peer, Samedan: Ediziun da l'Uniun dals Grischs e da la Lia Rumantscha, 1966 (Ouvras da Peider Lansel, Bd. 1).

Li Bai: Selected Poems, hg. von Yang Mushi, übers. von Xu Yuanchong, Changsha: Hunan People's Publishing House, 2007.

Li Bai: The Works of Li Po, übers. von Shigeyoshi Obata, London: J. M. Dent \& Sons, 1923.

Linji: Das Denken ist ein wilder Affe. Die Lehren des großen Zen-Meisters, übers. von Ursula Jarand, München: O. W Barth 2015.

Liu, Weijian: Kulturelle Exklusion und Identitätsentgrenzung. Zur Darstellung Chinas in der deutschen Literatur 1870-1930, Bern: Peter Lang, 2007 (Deutsch-Ostasiatische Studien zur interkulturellen Literaturwissenschaft, Bd. 7).

Miao Gao: An Analysis of Cultural Untranslatability with Eight Versions of Jing ye Si from with Experiential Metafunction, in: Advances in Social Science, Education and Humanities Research 232 (2018), S. 349-356, https://doi.org/10.2991/icadce-18.2018.74.

Moss, Lawrence: Three Chinese Poems for Cello and Soprano, Silver Spring: Selbstverlag, 1999.

Nagarjuna: Die Philosophie der Leere (Mulamadhyamaka-Karikas), übers. von Bernhard Weber-Brosamer und Dieter M. Back, Wiesbaden: Harrassowitz, 2005 (Beiträge zur Indologie, Bd. 28).

Nagarjuna: Die Lehre von der Mitte (Mula-madhyamaka-karika / Zhong Lun), übers. von Lutz Geldsetzer, Hamburg: Meiner, 2010, https://doi.org/10.28937/978-3-7873-1994-7.

Neumann, Robert: Li Tai Po. Ein deutscher Dichter, in: Die Neue Bücherschau 6 (1928), S. 77-81.

O'Brien, Flann: Der dritte Polizist, übers. von Harry Rowohlt, Frankfurt am Main: Suhrkamp, 1991.

Pan-Hsu, Kuei-Fen: Die Bedeutung der chinesischen Literatur in den Werken Klabunds. Eine Untersuchung zur Entstehung der Nachdichtungen und deren Stellung im Gesamtwerk, Frankfurt am Main: Peter Lang, 1990 (Europäische Hochschulschriften, Reihe I: Deutsche Sprache und Literatur, Bd. 1179).

Peduzzi, Lubomír: Musik im Ghetto Theresienstadt. Kritische Studien, Brno: Barrister \& Principal, 2005.

Penderecki, Krzysztof: 6. Sinfonie. Chinesische Lieder für Bariton und Orchester, nach Gedichten von Li-Tai-Po, Thu-Fu, Ly-Y-Han, Thang-Schi-Yie-Tsai und Tschan-Jo-Su in der Nachdichtung von Hans Bethge, Mainz: Schott, 2017 [S. 16-19].

Prieberg, Fred K.: Handbuch Deutsche Musiker 1933-45, Selbstverlag, 2009, online.

Puffet, Derick: The Song Cycles of Othmar Schoeck, Bern: Paul Haupt, 1982 (Publikationen der Schweizerischen Musikforschenden Gesellschaft, Bd. 32).

Schestag, Eva/Barrio Jiménez, Olga (Hg.): Von Kaiser zu Kaiser. Klassische chinesische Lyrik und Kunstprosa von der Han-Zeit bis zur Song-Zeit. Eine Anthologie, Frankfurt am Main: S. Fischer, 2009.

Schoeck, Othmar: »In der Herberge«, in: ders.: Lieder und Gesänge, Leipzig: Hug \& Co., 1907, S. 3 . 
Schollum, Robert: Das österreichische Lied des 20. Jahrhunderts, Tutzing: Hans Schneider, 1977 (Publikationen des Instituts für Österreichische Musikdokumentation, Bd. 3).

Schultz, Ingo: Viktor Ullmann. Leben und Werk, Kassel: Bärenreiter, 2008.

Seaton, Jerome P./Cryer, James: Bright Moon, Perching Bird. Poems by Li Po and Tu Fu, Middletown: Wesleyan University Press, 1987.

Seaton, Jerome P.: Bright Moon, White Clouds. Selected Poems of Li Po, Boulder, Colorado: Shambhala, 2012.

Sextus Empiricus: Grundriss der pyrrhonischen Skepsis, übers. von Malte Hossenfelder, Frankfurt am Main: Suhrkamp, 1985.

Silver, Philipp/Alder, Carine: James Simon, online, [o. J.], www.forbiddenmusicregained.org/ search/composer/id/102025 (Zugriff 20.03.2020).

Simon, James: "In der Fremde", in: ders.: Drei Lieder aus der chinesischen Flöte fuer eine Singstimme, mit Begleitung des Klavieres op. 10, Berlin: Dreililien, 1914, S. 4 f.

Smith, Cynthia L.: »Hallo, Hallo! Achtung! Achtung!...". A Performer's Guide to the Theresienstadt Compositions of Viktor Ullmann for the Mezzo-Soprano, Diss. Ball State University, Muncie, IN, 2014.

Ullmann, Viktor: »Wanderer erwacht in der Herberge«, in: ders.: Sämtliche Lieder für Singstimme und Klavier, Mainz: Schott, 2004, S. $176 \mathrm{f}$.

Vogel, Werner: Othmar Schoeck. Leben und Schaffen im Spiegel von Selbstzeugnissen und Zeitgenossenberichten, Zürich: Atlantis, 1976.

Wanek, Nina-Maria: Egon Wellesz in Selbstzeugnissen. Der Briefnachlass in der Österreichischen Nationalbibliothek, Wien: Österreichische Akademie der Wissenschaften, 2010 (Byzantina et Neograeca Vindobonensia, Bd. 27).

Webern, Anton: »In der Fremde«, in: ders.: Vier Lieder für Sopran und Kammerorchester op. 13, Wien: Universal, 1926 ['1917], S. 14-17.

Webern, Anton: Briefe an Heinrich Jalowetz, hg. von Ernst Lichtenhahn, Mainz: Schott, 1999.

Wellesz, Egon/Wellesz, Emmy: Egon Wellesz. Leben und Werk, hg. von Franz Endler, Wien: Paul Zsolnay, 1981.

Wells, Herbert George: Der Unsichtbare, übers. von Brigitte Reiffenstein und Alfred Winternitz, München: dtv, 1996.

Wittgenstein, Ludwig: Philosophische Untersuchungen, in: ders.: Tractatus logico-philosophicus, Tagebücher 1914-1916, Philosophische Untersuchungen, Frankfurt am Main: Suhrkamp 1984 (Ludwig Wittgenstein Werkausgabe, Bd. 1), S. 225-580.

Wolf, Christian: Musikerziehung unterm Hakenkreuz. Die Rolle der Musik am Beispiel der Oberschulen im Gau Tirol-Vorarlberg, Anif/Salzburg: Müller-Speiser, 1998 (Innsbrucker Hochschulschriften, Serie A: Musikpädagogik, Bd. 3).

Yu, Pauline: Judith Gautier and the Invention of Chinese Poetry, in: Reading Medieval Chinese Poetry. Text, Context, and Culture, hg. von Paul W. Kroll, Leiden: Brill, 2015 (Sinica Leidensia, Bd. 117), S. 251-288, https://doi.org/10.1163/9789004282063_011.

Zepf, Markus: Musik bewegt. Zu Lied und Musik der Jugend- und Singbewegung bis zum Zweiten Weltkrieg, in: Aufbruch der Jugend. Deutsche Jugendbewegung zwischen Selbstbestimmung und Verführung, hg. von Claudia Selheim, G. Ulrich Großmann und Barbara Stambolis, Nürnberg: Germanisches Nationalmuseum, 2013, S. 67-72. 
Mathias Gredig war wissenschaftlicher Mitarbeiter an der Hochschule der Künste Bern sowie Leiter des Archivs und der Bibliothek der Chesa Planta Samedan. Derzeit forscht er an der Universität Basel und dem Institut für Kulturforschung Graubünden zur Geschichte der Salonorchester im Engadin. Er promovierte mit einer Geschichte der skeptischen Zoomusikologie an der Universität Basel und ist Autor einer Studie zum Cellospiel von Daniil Schafran. 


\title{
Der doppelte Po und die Musik
}

Rätoromanisch-chinesische Studien, besonders zu

Li Po, Harry Partch und Chasper Po

\author{
Herausgegeben von \\ Mathias Gredig, Marc Winter, \\ Rico Valär und Roman Brotbeck \\ Redaktionelle Mitarbeit \\ Daniel Allenbach
}

Königshausen \& Neumann 
Bibliografische Information der Deutschen Nationalbibliothek

Die Deutsche Nationalbibliothek verzeichnet diese Publikation in der Deutschen

Nationalbibliografie; detaillierte bibliografische Daten sind im Internet über http://dnb.d-nb.de abrufbar.

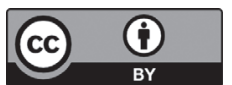

Dieses Werk ist lizenziert unter der Creative Commons Attribution 4.0 Lizenz (BY). Diese Lizenz erlaubt unter Voraussetzung der Namensnennung des Urhebers die Bearbeitung, Vervielfältigung und Verbreitung des Materials in jedem Format oder Medium für beliebige Zwecke, auch kommerziell. (Lizenztext: https://creativecommons.org/ licenses/by/4.0/deed.de) Die Bedingungen der Creative-Commons-Lizenz gelten nur für Originalmaterial. Die Wiederverwendung von Material aus anderen Quellen (gekennzeichnet mit Quellenangabe) wie z. B. Schaubilder, Abbildungen, Fotos und Textauszüge erfordert ggf. weitere Nutzungsgenehmigungen durch den jeweiligen Rechteinhaber.

Erschienen 2021 im Verlag Königshausen \& Neumann GmbH

(C) bei den Autoren

Die Druckvorstufe dieser Publikation wurde vom Schweizerischen Nationalfonds zur Förderung der wissenschaftlichen Forschung unterstützt.

\section{FNSNF}

SCHWEIZERISCHER NATIONALFONDS

ZUR FÖRDERUNG DER WISSENSCHAFTLICHEN FORSCHUNG

Wir danken der Kulturförderung des Kantons Graubünden.

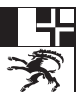

Kulturförderung Graubünden. Amt für Kultur

Promoziun da la cultura dal Grischun. Uffizi da cultura

Promozione della cultura dei Grigioni. Ufficio della cultura

SWIISSLOS

Hochschule der Künste Bern

www.hkb.bfh.ch

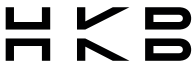

Hochschule der Künste Bern

Haute école des arts de Bern

Bern University of the Arts

Umschlag: skh-softics / coverart

Umschlagabbildung: Lea Gredig

Print-ISBN 978-3-8260-7180-5

PDF-ISBN 978-3-8260-7233-8

DOI $10.26045 /$ po

https.//doi.org/10.36202/9783826072338

Gedruckt auf säurefreiem, alterungsbeständigem Papier

Printed in Germany

www.koenigshausen-neumann.de

www.ebook.de

www.buchhandel.de

www.buchkatalog.de 


\section{Inhalt}

Prolog

Dumenic Andry

Chasper Pos Humor

Renzo Caduff

Chasper Pos rhythmische Versgestaltung - eine shinkende Mähre`?

Rico Valär

Rätoromanische Nachdichtungen chinesischer Lyrik bei

Gian Fadri Caderas und Peider Lansel

Eine Spurensuche

Mathias Gredig

China in rätoromanischen Zeitungen, Zeitschriften

und literarischen Texten

Marion Eggert

Schwalbenflug in Gedichten von Li Bai und Chasper Po

Thomas Geissmann

Die Rolle der Gibbons beim chinesischen Dichter Li Bai

Marc Winter

„Chinas Dichterfürst«

Die Rezeption Li Bais als literarischer Superstar im Westen

Eva Schestag

"A most difficult man«

Ezra Pound als Übersetzer von Li Bai, mit einem Seitenblick auf Shigeyoshi Obata

Odila Schröder

Chinesische Li-Bai-Vertonungen in Jahren der Unruhe 
Mathias Gredig

Quantitative Überlegungen zum Phänomen

der Li-Bai-Vertonungen im Westen

Mit Beobachtungen zu drei Vertonungen des Gedichtes

Chun ye Luo cheng wen di (In einer Frühlingsnacht in Luoyang eine Flöte hören)

\section{Gesine Schröder}

"Die Hüften schwingen sich nun nicht mehr»

Li-Bai-Vertonungen von Komponistinnen

Heinrich Aerni

Li-Bai-Vertonungen in der Schweiz

Matthias Schmidt

Übersetzung ohne Original?

Gustav Mahler, Anton Webern und Li Bai

\section{Christoph Haffter}

Szenen der Selbstenttäuschung

Hanns Eislers Die rote und die weiße Rose nach Li Bai und die Antinomien der Kriegslyrik

Thomas Meyer

„Wunderlich im Spiegelbilde»

Zu einigen Vertonungen des Pavillon-Gedichts

\section{Mathias Gredig}

Gedanken über Li Bais Jing ye si (Gedanken in einer stillen Nacht)

und dessen Vertonungen im Westen

\section{Martin Skamletz}

"I've turned into a great reviser."

Lee Hoibys Vertonung von Li Bais The River-Merchant's Wife: A Letter

und ihr Bezug zu Harry Partch

\section{Martin Skamletz}

"Of course I am a weak shadow of Lee Hoiby as a Kitharist."

Five letters by Harry Partch, 1948-1958

\section{Marc Kilchenmann}

Ben Johnstons Verhältnis zu Harry Partch und seine Three Chinese Lyrics 
Eleni Ralli

Parallelen und Modifikationen der Notation in verschiedenen Quellen

von Harry Partchs Seventeen Lyrics by Li Po

Schwierigkeiten und Transkriptionsvorschläge

Charles Corey

Gesture and Intention in the Art Songs of Harry Partch

Caspar Johannes Walter

Sprechmelodie als Quelle von Melodik und Harmonik

The Intruder aus Harry Partchs Li-Bai-Vertonungen

Roman Brotbeck

Der Sprechgesang bei Arnold Schönberg und Harry Partch

Eine Annäherung

Namensregister 